College of Psychiatrists), Dr D. Kelly (Medical Director, The Priory Hospital), Dr S. A. Mann (Member, Executive and Finance Committee), Professor J. Watson (Professor of Psychiatry, Guy's Hospital) In attendance: Mrs Vanessa Cameron (Secretary), Ms Deborah Hart (Assistant Secretary)

\section{References}

Royal College of Psychiatrists(1988) The Royal College of Psychiatrists' comments on the Griffiths Report
'Community Care: Agenda for Action'. Bulletin of the Royal College of Psychiatrists, 12, Section II (para iii), 385-386.

(1988) Psychiatric Beds and Resources: Factors Influencing Bed Use and Service Planning. Report of a Working Party of the Section for Social and Community Psychiatry of the Royal College of Psychiatrists. London: Gaskell (RCP).

- (1989) A statement on attendance of Health Authority Officers at Consultants' Advisory Appointments Committees. Psychiatric Bulletin, 13, 104.

\title{
Trainees' forum: How to survive in management
}

\author{
LisetTa M. LovetT, Lecturer in Psychiatry, Department of Psychiatry, University of \\ Liverpool, Liverpool
}

On 23 January at the Winter Quarterly Meeting 1989 , one week before publication of the White Paper on the Review of the NHS, the Trainees' forum, entitled 'How to Survive in Management', took place. The decision to devote this forum to management issues was taken in September 1988 at the CTC's Residential Meeting where there was little hesitancy from trainees in identifying this subject as important, topical and worthy of a forum. There were three speakers who each talked for 20 minutes before the floor was opened to discussion. Below is an outline of these talks and the key issues which arose afterwards.

Dr McKim Thompson, who is a Deputy Secretary of the British Medical Association, was the first to speak. He stressed how important it is for doctors to take an active interest in management and for trainees to find the 'willpower' to acquire some training. He told us that in some Regions, consultant appointments are not made when the senior registrar has not acquired specific management training. After giving us a multi-faceted definition of management, he examined some specific issues which any doctor involved in management should address. These included an understanding of industrial relations (which is complex within an organisation which has 42 unions), terms of service, and disciplinary procedures. He stressed the importance of discovering as an aspirant consultant, how a service is being delivered at a local level. He stressed the need to talk to local consultants in your own and other specialties.
Dr McKim Thompson concluded with suggestions for personal management training. He advised trainees to be alert to advertisements on courses in journals and periodicals. He suggested that initially, attendance at a unidisciplinary course is advisable, that is one targeted at doctors or even psychiatrists only, rather than several different health care professionals. He recommended a number of interested organisations which offer courses in conjunction with the BMA, which include the International Business Management Services at Aston and the Health Services Management Centre at Birmingham. He expressed a BMA concern that consultants, particularly in psychiatry, were abdicating a leadership role and apropos this, he recommended that trainees should acquire training in interpersonal skills, communication and team leadership. Additionally, he stressed the importance of developing an understanding of planning and financial management, funding of the NHS, and Department of Health procedures. Like the next two speakers, he emphasised the need to develop skills in personal time management.

Our second speaker was Dr Master, who had held the post of Director of the Mental Illness Services at Guy's Hospital for the last 18 months. He started by pointing out how doctors and managers come from ideologically different backgrounds which may account for the lack of interest which most doctors have for involving themselves in management. Whereas doctors are concerned with short-term goals for their individual patients, regardless of cost, 
managers must attend to both longer term goals, within the constraints of limited resources, and to the interests of the organisation. He then described how Guy's came to change its own management organisation. In 1984, spurred by funding restrictions imposed by RAWP, closure of beds and pay award shortfalls, a group of clinicians and senior managers visited Johns Hopkins in Baltimore to study its decentralised management system. As a result, Guy's was divided into 14 clinical directorates, each headed by a clinical director and supported by a nurse and manager. This unique model for health care management is designed to encourage participation from all health employees and to ensure that each director takes responsibility for a number of facets of health care, from overseeing clerical staff to quality assurance, as well as taking charge of an annual budget which at Guy's is $£ 11$ million; all services associated with care and treatment both in hospitals and in the community are funded from this. The director, who is managerially accountable to the unit general manager, has complete freedom on how to plan that budget and on deciding on the annual objectives to be achieved. These objectives are usually embodied in a one year plan which is produced at the beginning of each financial year called the business programme. This is part of a longer ten year strategic plan produced by the health authority and a two year rolling short-term plan. The business programme concerns itself with specific day to day issues such as outpatient case loads and costing.

Dr Master pointed out that a clinical director, although supported by a full-time chief executive, must have sufficient time outside clinical duties to devote to his managerial responsibilities. He showed us some interesting recent balance sheets on expenditure which revealed the problems of overspending on the nursing budget, due to chronic understaffing and consequent expense on overtime and agency nursing, compared to relative underspending on other mental illness services. He pointed out how helpful it was to have monthly data on expenditure in order to regain control by modifying procedures as necessary.

Dr Master concluded his interesting talk by sharing some of his own experience with us as a clinical director. He regretted having no formal training when he was first appointed. He stressed that there were certain fundamental tenets to being an effective director. These included having an understanding of your organisation, having adequate, up-to-date information and overall longterm goals as well as being able to carry your medical colleagues towards those goals: "management is about what needs to be done and then trying to deliver the goods".

We were pleased to have as our final speaker Dr Thornley, Director of Personnel and Administration at Shell UK. He suggested that the NHS like any other organisation is similar to a living organism which should be concerned with survival, growth and adaptability. He admitted that he found the NHS management structure more complex than that in Shell. He then described the process of management training within Shell. This consists of moving to different managerial roles at least every three years, thereby avoiding stagnation. His personal tip was that the best way to learn about the rules of management is to observe "the good players". He elaborated on the Shell system of both careful recruitment and subsequent training coupled to annual review of personnel. Shell is increasing adopting the view that the most effective method of training is 'hands-on' experience underpinned by a knowledge base.

\section{Comment}

The discussion which followed the three talks highlighted a variety of issues which concern psychiatric doctors about their putative role in management. These included the practical issue of how much time should be spent away from clinical duties and devoted to managing. Dr Master told us that he was allocated five sessions for management as a clinical director but in fact spent more time on his management duties than this. One questioner wanted to know particularly how much time he thought the average consultant needed to spend. At Guy's, in addition to informal talks with individuals, Dr Master meets fortnightly with all consultants. This implies considerable time spent communicating with colleagues on management issues even for those consultants who do not hold an established managerial role. The importance of good communication arose again when someone questioned how to deal with decreasing morale amongst NHS employees.

Discussion broadened into the ideological difference between industry and the NHS where the main obligation for the former is the organisation whereas for the latter it is the patient. Dr Thornley suggested that these different objectives needed integration if the NHS was to become a successful business. But in what terms do you define objectives? Dr Master pointed to the controversy over judging and quantifying performance. Interestingly, Dr Thornley's view was that performance assessment is a qualitative process and that it is not based on strict outcome criteria. It seems that the notion of industry assessing outcome on profitability alone may be a myth.

The question of curtailed clinical freedom was raised in relation to constraints on consultants to ensure they stayed within budgets. Dr McKimThompson suggested that clinical freedom was a 
myth and that peer pressure would protect against overspending amongst consultants. According to him, the days of over-spending as a strategic ploy have long since disappeared.

Training issues also arose. It was pleasing to hear that Shell is prepared in principle to undertake to train NHS trainees if the goals are welldefined and the association can prove mutually beneficial; they already have experience of training Civil Service employees and head teachers. One questioner expressed concern about how trainees were to get comprehensive management training when funding is increasingly limited and he raised the question of how doctors should react to unpopular management decisions which they know will make the NHS more difficult to run. Dr Master suggested that there are two responses to this situation: either you do not cooperate and make a fuss, thereby risking an outside auditor being brought in to manage, or you challenge from within the system. He prefers the latter option which he feels allows one to retain control. This sentiment was echoed by Dr Thornley who told us that the unpopular management decision from above is also a problem for personnel in industry. The practical way to deal with this is to demonstrate clearly to top management how services will be affected by new constraints and what problems will arise. It is the role of a manager to challenge, otherwise one ends up as a mere cypher. That challenge may lead to a total re-examination of the whole organisation, which perhaps is not a bad thing.

\section{Appointments of consultant locums}

In 1984 the Court of Electors prepared a Memorandum giving advice on locum consultant appointments. This was included in the Handbook of the Joint Committee on Higher Psychiatric Training. However, it did not receive a wider circulation.

Council has recently approved this document with some minor revisions. It emphasises that locum appointments should only be made after careful consideration and for short periods of time. The person must have received appropriate training. A long-term locum consultant appointment is not a substitute for higher training in an approved senior registrar training scheme.

\section{Recommendations}

(1) No doctor should be appointed to a short-term locum consultant post who has not been sufficiently trained to assume all the responsibilities of a consultant. This limits those eligible to:

(a) recently retired consultants

(b) senior registrars within a short time of completion of training for whom only three months locum consultant experience is recognised for the purposes of higher training

(c) fully trained senior registrars or others suitably qualified and experienced, who are not yet ready to commit themselves to a permanent consultant post, or who would never wish to do so

(d) those trained under other comparable systems recognised by the College (e.g. overseas) but whose training has not necessarily been identical in form and content.
(2) The criteria of eligibility for appointment to consultant status produced by the College are respected by employing authorities (with statutory support) and are designed to provide acceptable standards for the safety and care of patients. It would therefore be wrong to waive them for short-term appointments. A statement of these criteria is sent to all College Representatives on Advisory Appointments Committees.

(3) These guidelines should apply to all locum posts. Where it is anticipated that the locum arrangement will last for more than three months a full Advisory Appointments Committee should be convened.

If the locum arrangement has lasted for more than three months an Advisory Appointments Committee should be convened to decide whether the arrangement should continue. Locum arrangements should not normally be continued beyond three months unless there are explicit and defined reasons.

(4) No appointment should be confirmed until the local consultants or their representatives have personally checked the applicant's references with his/her former colleagues. This should be a mandatory provision.

(5) If applicants for short-term locum consultant posts do not meet the conditions under (1) then either:

(a) no appointment should be made

(b) an appointment should be made at a grade appropriate to the needs of the service. If an appointment is made to a training grade, consideration should be given to the educational 